\title{
The Study of the Effectiveness of Textual Cohesion of Teaching Materials on Iranian Intermediate EFL Learners' Reading Comprehension
}

\author{
Hengameh vaezi \\ Assistant professor, Department of English Language,Islamic Azad University, Rasht Branch,IRAN \\ Shahnaz Habibi Gavabari, \\ Department of English Language,Islamic Azad University, Rasht Branch,IRAN
}

\begin{abstract}
The present investigation was an attempt to study the effect of difference in textual cohesion of different teaching materials on Iranian intermediate EFL learners' reading comprehension. To that end, a QPT test was administered to $105 \mathrm{EFL}$ students learning English language in institutes. Based on QPT test direction individuals who get $31+$ in grammar and vocabulary, $8+$ in reading section, and $8+$ in writing are considered to be at intermediate level of foreign language proficiency. So 45 learners were selected for this study and they were divided into three groups, two experimental groups and one control group, the first experimental group, studying Topnotch, the second experimental group studying Touchstone and the control group studying high school English book. All groups contained 15 participants. Then a reading test was administered to all groups as a pre-test to take their initial knowledge of reading comprehension. The experimental groups received treatment in using the above mentioned books containing more cohesive elements in ten sessions. The control group was taught the high school English book reading passages. Finally all experimental and control groups sat for the posttest for reading comprehension test. ANOVA was conducted to see if there was a significant difference between groups or not. The results were computed and analyzed through SPSS and it was explored that difference in textual cohesion in different teaching materials, namely texts containing more cohesive elements, had a positive effect on Iranian intermediate EFL learners' reading comprehension ability.
\end{abstract}

Keywords: cohesion, cohesive devices, reading comprehension, learning.

DOI: $10.7176 / J L L L / 52-03$

\section{Introduction}

Understanding the two important features of discourse, coherence and cohesion, is important for a better understanding of the purpose of this study, as it specifically focuses on the use of text cohesion during meaning representation and the construction process. Generally spoken, cohesion is used to refer to the surface indicators of relations between sentences in a text (Graesser, McNamara \& Louwerse, 2004), which contain semantic meaning relations. It is the set of possibilities in the language that allow for the text to hang together (Halliday \& Hasan, 1976).

Coherence, when separated from cohesion, implies that a long stretch of language is semantically and meaningfully connected. Coherence has been approached from different perspectives by different researchers. Some researchers view coherence as a linguistic, text-based entity, some others regard it as non-linguistic, that is, reader-based. Halliday and Hasan as the first scholars to elaborate on cohesion (1976, p. 52) defined coherence as the logical flow of ideas, a connectivity of the surface text evidenced by the presence of cohesive devices. Coherence has also been defined as the means by which readers construct a mental model of a text (Carrell, 1982; Graesser et al., 2004). According to Graesser and his colleagues (Graesser et al (2003), the coherence of a text is defined by the interaction between linguistic representations and knowledge representations. When you put the spotlight on the text, however, coherence can be defined as characteristics of the text (i.e. aspects of cohesion) that are likely to contribute to the coherence of the mental representation.

The concept of cohesion defined by Halliday and Hasan has been criticized in the light of schematheoretical views of text processing (Carrell, 1982). This criticism attempted to show that Halliday and Hasan's cohesion concept, which encourages the belief that coherence is located in the text and can be defined as a configuration of textual features, fails to take the contributions of the reader into account (Carrell, 1982). However, in his theory of language, Halliday possibly did not propose that cohesion alone could account for text coherence.

Halliday and Hasan (1976) interpret cohesion as "the set of semantic resources for linking a sentence with what has gone before," In Halliday and Hasan's definition, "A text is a passage of discourse which is coherent in two regards: it is coherent with respect to the context of situation, and therefore consistent in register; and it is coherent with respect to itself, and therefore cohesive" (p. 23). According to Halliday and Hasan (1976), the primary factor of whether a set of sentences does or does not constitute a text depends on cohesive relationships 
between and within the sentences, which create texture. Graesser and his colleagues (Graesser, McNamara \& Louwerse, 2003) state that the coherence of a text is defined by the interaction between linguistic representations and knowledge representations. When you put the emphasis on the text, coherence can be defined as characteristics of the text (i.e. aspects of cohesion) that are likely to contribute to the coherence of the mental representation.

In all definitions provided by different researchers, cohesion that contributes to text coherence plays an important role because relationships between propositions determine the connectivity of the underlying concept, and these relations contribute to the overall discourse theme and organization (Kintsch, 1998). The continuity expressed by cohesion in a text shows, at each stage in the discourse, the points of relations or contact with what has been said before. On the other hand, the continuity provided by the cohesion helps the readers to fill gaps in the discourse, and to supply all the components of the message, which are not present in the text but are important and necessary to its interpretation.

Considering the important contribution of cohesive devices to texture, readability and comprehensibility of a text, scholars have provided a number of taxonomies for cohesion, which share some common categories. Halliday and Hasan (1976) identify and classify cohesion into five categories: reference, substitution, ellipsis, conjunction, and lexical cohesion. The first four of these types are called grammatical cohesion. Hinkel (2001) lists features of cohesion: phrase-level connectors, sentence transitions, logical/semantic conjunctions, demonstrative pronouns, enumerative nouns, and resultative nouns.

Text coherence and comprehension studies have been conducted on the interaction between different levels of meaning representation during comprehension, such as the effect of text cohesion on reading comprehension (O'Reilly \& McNamara, 2007), the relationship between textual coherence and reading inferences (Horiba, 1996), and the interactions of text coherence and background knowledge (McNamara et al, 1996; 2001). Most of the L1 studies examined the relationship between text cohesion and inferencing by specifically including reader's domain knowledge (McNamara et al., 1996; O’Reilly \& McNamara, 2007).

Text comprehension is a complex process that is dependent on many factors. It can be placed in two categories of factors including individual characteristics of the reader and the text. Individual characteristics such as Readers of previous knowledge, skills, and characteristics of the text such as text cohesion and structure. Comprehension is the complex interaction between individual differences and characteristics of the text. The results of the PIRLS (Progress in International Reading Literacy Study) reading indicate more than 60 percent of Iranian students are poor and very poor in the comprehension. Several factors affect students' reading Comprehension. Snow 2002 quoted the four factors are effective in improving reading include the reader characteristics, text characteristics, Comprehension strategies, and social and cultural situations.

\subsection{Statement of the Problem}

Reading comprehension is a very complex process and in order to grasp who readers make sense of written symbols, it is essential that the process of reading comprehension and the role of factors leading to the product of this process be understood properly. Generally, two factors may influence reading comprehension: internal and external (Sadeghi, 2007). Internal factors, called reader variable, refer to everything related to the reader such as his /her cognitive abilities and strategies, background knowledge and effective characteristics.

External factors, called text variable, context variable and writer variable, refer to all factors external to the reader. Context variable refers to all situational elements such as the time of reading and the place of reading as well as the larger socio-economic context. Writer variable refers to the text producer. There is little dispute among researchers that the reader plays the central role in an act of reading. While the reader was once believed to be a passive receiver of information, he/ she is now considered an active participant in a reading activity (Chastain, 1988; Sadeghi, 2007). Because of importance of reading comprehension in language instruction and particularly the necessity of undertaking and comprehending various texts at academic level, there seems to be still an increasing need and space for conducting more research in this field.

Various theories and works have been a part of growing body of ESL and EFL reading research as well as investigations concerning cohesion and coherence as subcategories of communicative competence and textually important factors in reading comprehension. This study will try to identify the effect of textual cohesion of teaching materials on EFL Iranian learners' reading comprehension ability.

\subsection{Research question}

To fulfill the objective of the study, the following research question was proposed:

1. Does the difference in textual cohesion of different teaching materials have any significant effects on Iranian intermediate EFL learners' reading comprehension?

\subsection{Research Hypothesis}

$\mathrm{H}_{0}$ : the difference in textual cohesion of different teaching materials has no significant effects on Iranian 
intermediate EFL learners' reading comprehension.

\section{Cohesion and Texture}

The concerns of applied linguistics swing pendulum-like between focus on larger and smaller elements. Thus, from a pre-occupation with segmental sounds just a decade ago, phonetics is now switching its attention to areas such as intonation discourse. Similarly, from the Rhetoric of the days of Aristotle, the pendulum swung to Chomsky's sentence-constrained transformational grammar, and now back to concern with texture, i.e. the properties that characterize text and that distinguish it from non-text. This means what can be considered and understood as text comprehensible for a reader.

Language-teaching, in drawing on the attention of applied linguistics, has also in recent years concerned itself increasingly with the essential characteristics of text. Thus, in reading, we are today less occupied with the minutiae of words and word-parts, and more with texture. One important aspect of texture is cohesion.

Textual cohesion is a semantic concept. It is concerned with semantic relations within a text (both within and between sentences), such that the reader's ability to interpret a particular textual element depends on his ability to interpret another element. The elements are tied: thus we talk of cohesive ties in text. And inter-element semantic cohesion is one of the major features that enable a fluent reader to distinguish text from a random string of discrete sentences.

\section{Experiments on Textual Cohesion in EFL Situation}

Mozaffar-Zadeh (1998), analyzed ellipsis and substitution in science books at guidance level and concluded that Halliday and Hasan's classification (1976) on ellipsis and substitution can be extended to Persian. Tseng and Liou (2006) inquired about the effects of on line conjunction materials on college EFL students writing. They argued that inappropriate utilization of conjunction in English, which leads to incoherent writing, is because of first language interface, misleading lists of connectors, and improper exercises. They also informed that pedagogical instructions for teaching online conjunction materials would assist EFL learners to have more writing that are coherent.

Roberts (2009) following Dooley and levinsohin's (2001) analytical methodology described different aspects of discourse analysis including an introductory description of cohesion and coherence in 16 Iranian stories. They have also shown the style of working on discourse studies in Persian language. They have stated that their study is just an introductory work which guide people in knowing how discourse studies in Persian can be managed based on Dooly and levinsohin (2001). In analyzing cohesive ties in English as a foreign language student's writing. Rostami and Abu-saeedi (2010) investigated about the most frequently used cohesive device in his sample. He came to surprising, conclusion. Poor student were expected to have low density of cohesion because they could not combine sentences together coherently, e.g. by the use of conjunctions.

Seddigh, Shokr-pour and Kafi-pour (2010) analyzed, lexical cohesion in English and Persian abstracts based on Seddigh and Yarmohamadi's (1996) lexical cohesion framework. They use the SPSS package for contrastive analysis. The results indicated that there were some similarities and differences in the application of lexical cohesion in their corpus. All sub-type had nearly the same occurrences in the two sets of data and the two-tailed t-test revealed that the differences between their applications in English and Persian abstracts are not statistically significant. Both languages reported repetition as the most frequent sub-type, but synonymy and meronym were the least used-categories.

More recently, Yang and Sun (2012) explored the use of cohesive devices in argumentative writing by Chinese sophomore and senior EFL learners. The results of ellipsis and substitution analysis revealed that the two devices were mostly found in spoken language and were seldom used in formal written discourse. About $56.67 \%$ of the sophomores and $70 \%$ of the seniors had not used these devices; because they had become aware of the inappropriateness of using ellipsis and substitution in formal writing.

\section{Materials}

To answer the research question of this study, the following instruments were used:

\subsection{Oxford Quick placement Test (QPT)}

The Quick Placement Test (QPT) is a flexible test of English language proficiency developed by Oxford University Press and Cambridge UCLES to give teachers a reliable and time-saving method of finding a student's level of English. It is quick and easy to administer and is ideal for placement testing and examination screening. There are two versions available, a computer-based $(\mathrm{CB})$ version and a paper and pen (P\&P) version. In order to check the level of general language proficiency of students at the beginning of the study, and to make sure of their homogeneity, an Oxford Placement Test was used. 


\subsection{Pretest}

The purpose of this test administered before the treatment is to find the possible initial differences between reading comprehension ability in the experimental and control groups. In so doing, a reading test including 20 multiple choice questions, related to reading comprehension, was used to test the participants' reading comprehension ability.

\subsection{Posttest}

This test which is administered after the treatment sessions is parallel in all respects to pretest except for the topic of the question. In fact, another version of the reading test, including 20 multiple choice questions was used to test the participants' reading comprehension after the interventions.

\subsection{Text books}

High school English book, Top-notch and Touchstone text books were used in this study. Each lesson of high school English book contains new words, reading, speak out, writing, language function and pronunciation parts. Top notch and Touchstone text books contain conversation, vocabulary, grammar, listening comprehension, speaking, pronunciation, and reading sections.

\section{Procedure}

At the outset, a homogeneity test in terms of the participants' general proficiency was administered. With regard to making a homogeneous group, the researcher used QPT (Version 1) for the overall number of 105 learners who were studying English as a foreign language in Shokouh and Simin English Institutes in Roudsar, Iran. Notably, the learners were comprised of female learners in the 16-20 age range. In order to check the level of general language proficiency of students at the beginning of the study, and to make sure of their homogeneity, an Oxford Placement Test was used. (See Appendix A). All participants in three intact classes sat for this test. The participants took four parts that included items related to structure, vocabulary, reading, and writing with a maximum possible score of (70) points.

Among the total number of learners who sat for this test, based on QPT direction individuals who got 31+ in grammar and vocabulary , $8+$ in reading section, and $8+$ in writing were considered to be at intermediate level of foreign language proficiency. Those who obtained these scores were about 45 learners. They were assigned into two experimental groups and one control group.

A pretest of reading comprehension was administered to the groups. After that, two experimental groups receive 10 -sessions treatment during which they encounter textual cohesion in teaching materials using the reading sections of the books that used at the institutes are named Topnotch and Touchstone. The control group received the same treatment with only difference which was the teaching materials. For the control group, the readings of the high school English book were used. After the treatment all groups were given a posttest of reading comprehension.

\section{Results}

The main purpose of the present study was to inspect empirically the possible effects of awareness raising of textual cohesive factors on Iranian intermediate EFL learners' reading comprehension performance. Descriptive statistics were run to the results of the Oxford Placement Test and $(\mathrm{N}=45)$ intermediate EFL learners were selected based on Oxford Placement Test Direction. Then, they were randomly divided into three groups. Reading comprehension tests were given to the three groups both at the beginning and at the end of the study. The main data was collected from the findings of pre and posttests of reading comprehension to the three groups. One-way Analysis of Variance (ANOVA) was run to the results of the pretest of reading comprehension to investigate their initial capability in terms of reading comprehension. Afterwards, the specific instruction on textual cohesive elements was presented to the three groups. After initiating the specific treatments to the three groups, a posttest of reading comprehension was directed to the groups.

To supply answer for the research question, One -Way ANOVA procedure followed by Post- Hoc Scheffe test were run to the results of the posttest of reading comprehension. This test provided analysis of variance for the dependent variable (i.e. reading comprehension ability) by the specific factor (i.e. types of materials in terms of the extent of cohesive elements) to scrutinize which type of textbooks was effective for improving the participants' reading comprehension performance.

Prior to running the main statistical analyses of the present study, normality that is the main presumption of the parametric tests was settled for all of the distributions through running Leven Test, and displaying Error Bars Furthermore, the reliability of the reading comprehension tests was estimated through running Cronbach's Alpha in a pilot study. 


\section{Descriptive Statistics for the Pretest Scores of the Reading Comprehension}

At the beginning of the study, all the participants attended the pre-test. The main goal was to set up a baseline measurement from which the participants' achievements on the post-test could be examined and explained. Table 1 and 2 reveal the results of One-Way ANOVA used to analyze the participants' scores in the pretest of reading comprehension.

Table 1

Group Statistics for the Pretest Scores of the Three Groups

\begin{tabular}{|c|c|c|c|c|c|c|c|c|}
\hline 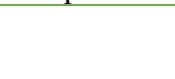 & \multirow[t]{2}{*}{$\mathbf{N}$} & \multirow[t]{2}{*}{ Mean } & \multirow[t]{2}{*}{$\begin{array}{c}\text { Std. } \\
\text { Deviation }\end{array}$} & \multirow[t]{2}{*}{$\begin{array}{l}\text { Std. } \\
\text { Error }\end{array}$} & \multicolumn{2}{|c|}{$\begin{array}{l}\text { 95\% Confidence } \\
\text { Interval for Mean }\end{array}$} & \multirow[t]{2}{*}{ Minimum } & \multirow[t]{2}{*}{ Maximum } \\
\hline & & & & & $\begin{array}{l}\text { Lower } \\
\text { Bound }\end{array}$ & $\begin{array}{l}\text { Upper } \\
\text { Bound }\end{array}$ & & \\
\hline $\begin{array}{l}\text { high school } \\
\text { textbook }\end{array}$ & 15 & 13.53 & 1.55 & .40 & 12.67 & 14.39 & 11.00 & 15.00 \\
\hline Top-notch & 15 & 13.66 & 1.54 & .39 & 12.81 & 14.52 & 11.00 & 16.00 \\
\hline touchstone & 15 & 13.86 & 1.88 & .48 & 12.82 & 14.91 & 11.00 & 17.00 \\
\hline Total & 45 & 13.68 & 1.63 & .24 & 13.19 & 14.18 & 11.00 & 17.00 \\
\hline
\end{tabular}

The descriptive table revealed the sample size, the mean, the standard deviation, and the standard error for all the three groups at the beginning of the study. For the pretest of reading comprehension, the means for the group $\mathrm{A}$ (who worked on high school textbooks) came to $\left(\mathrm{X}^{-}=13.53\right)$, that for group $\mathrm{B}$ (who worked on topnotch) amounted to $\left(\mathrm{X}^{-}=13.66\right)$, and for group $\mathrm{C}$ (who worked on touchstone) equaled $\left(\mathrm{X}^{-}=13.86\right)$. They differed some points around their average. The mean score of group $\mathrm{C}$ was (.20) points higher than that of group $\mathrm{B}$ and (.33) points higher than group A.

In addition, the degree of variation of the scores for group $\mathrm{C}\left(\mathrm{SD} \mathrm{C}_{\mathrm{C}}=1.88\right)$ was slightly higher than the extent of dispersing of scores around the mean score for groups $(A)$ and $(C)\left(S D(A)=1.55 ; \mathrm{SD}_{B}=1.54\right)$. The ANOVA examined whether these differences in the mean scores of the three groups were statistically significant before presenting the particular treatments to the groups.

Table 2

One-way ANOVA for the Pretest Scores of the Control and Experimental Groups

ANOVA

\section{pretest scores}

Between Groups

Within Groups

Total

According to Table 2, there was no meaningful difference between the mean scores of the three groups in pre-test of reading comprehension $(\mathrm{p} \geq .05)$. This meant that, the groups were almost at the same level of proficiency with respect to their reading comprehension ability at the beginning of the study before introducing the specific treatment to the experimental groups.

The descriptive statistics for the reading comprehension posttest is presented in Table 3 below: Table 3

Descriptive Statistics for the Posttest Scores

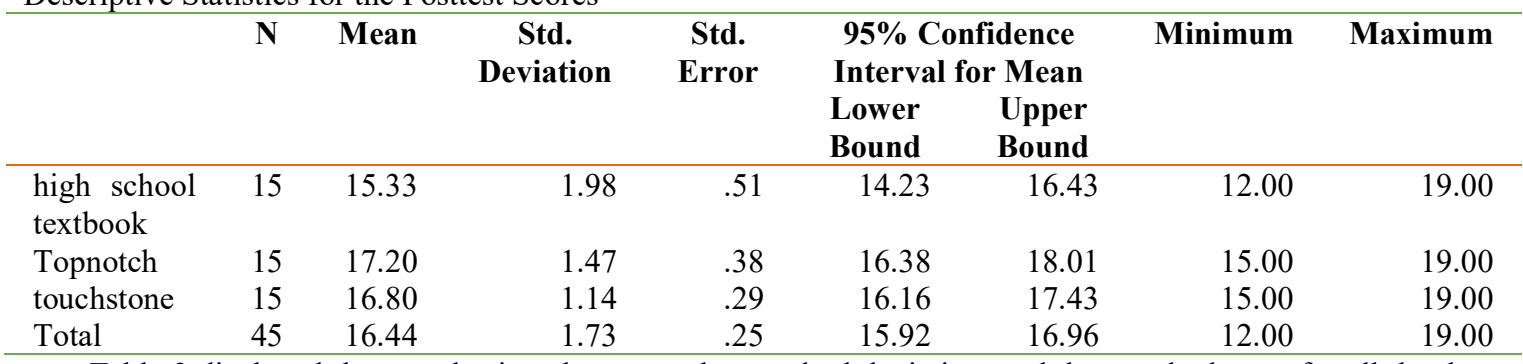

Table 3 displayed the sample size, the mean, the standard deviation, and the standard error for all the three groups at the end of the study. For the posttest of reading comprehension, the means for the group A (who worked on high school textbooks) came to $\left(\mathrm{X}^{-}=15.33\right)$, that for group B (who worked on top- notch) amounted to $\left(\mathrm{X}^{-}=17.20\right)$, and for group $\mathrm{C}$ (who worked on touchstone) equaled $\left(\mathrm{X}^{-}=16.80\right)$. They differed some points around their average. The mean score of the group B was (1.87) points higher than that of group (A) and (.40) points higher than group $(\mathrm{C})$.

Furthermore, the degree of scatteredness of the scores for group A ( $\left.\mathrm{SD}_{\mathrm{A}}=1.98\right)$ was slightly higher than the extent of dispersion of scores around the mean score for groups $(B)$ and $(C)\left(S D{ }_{B}=1.47 ; S_{C}=1.14\right)$. The ANOVA examined whether these differences in the mean scores of the three groups were statistically significant 
before providing the three groups with the three different materials regarding their textbook that they worked on for their EFL classes.

Table 4

ANOVA for the Results of the Reading Comprehension Test (Posttest)

\begin{tabular}{lrrrrr}
\hline & Sum of Squares & df & Mean Square & F & Sig. \\
Between Groups & 28.978 & 2 & 14.489 & 5.844 & .006 \\
Within Groups & 104.133 & 42 & 2.479 & & \\
Total & 133.111 & 44 & & & \\
\hline
\end{tabular}

The results showed that $F(2,42)=5.844, p<.05$, therefore, It was found statistically significant difference between the three sets of scores. . Figure 1 illustrates the means plot for the results of the posttest of reading comprehension.

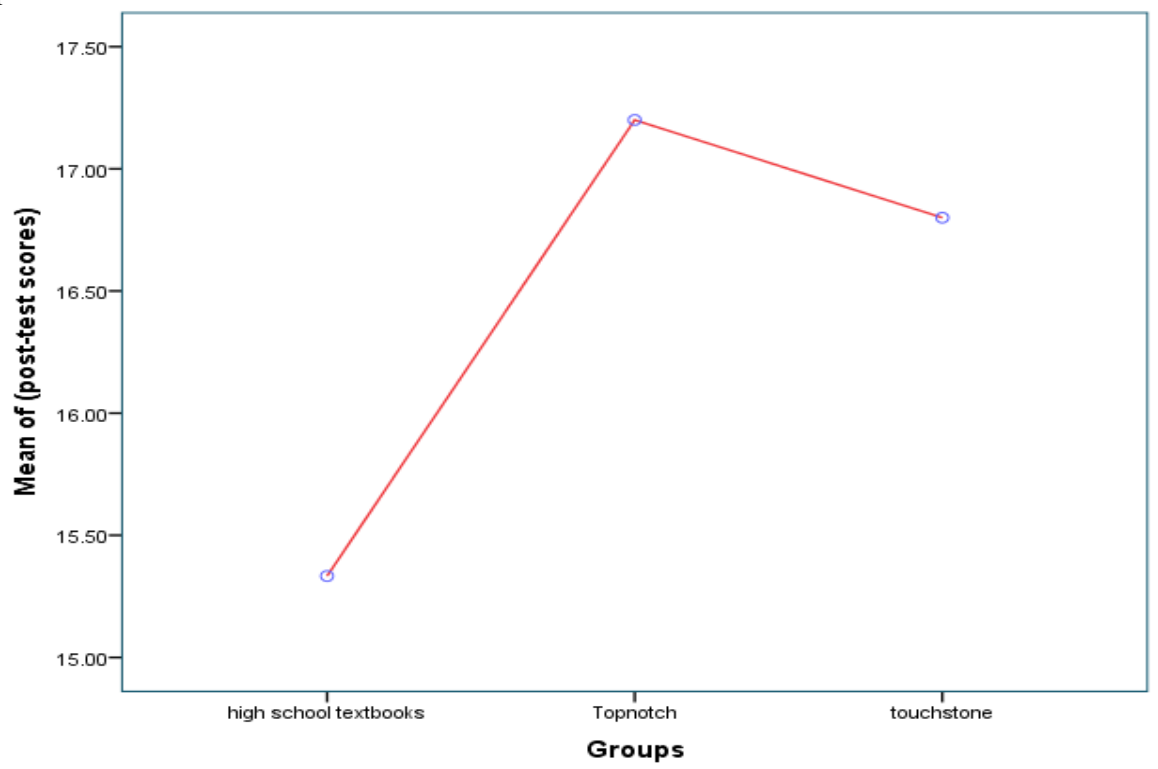

Figure 1: Means plot for the results of the reading comprehension (posttest)

In general, $F$ statistics in Table 4, firmly settled that there were statistically significant differences among the three groups' means, and means plots exposed the position of these differences. The participants of (B) who had worked on top- notch series that had rich cohesive elements outperformed their counterparts including group (A) who had worked on high school textbook which lacked rich cohesive elements and group (C) who worked on touchstone which included cohesive elem0ents moderately. This rejected the first null hypothesis implying that providing instruction on textual cohesive elements has statistically significant effect on Iranian EFL learners' reading comprehension.

After it was revealed that the groups differed in some way, post- hoc test displayed more about the structure of the differences. In other word, doing multiple comparisons Post- hoc test (Scheffe) was employed for comparing the means of the three groups.

Table 5

Multiple Comparisons for the Results of the Posttest

Scheffe

(I) group

(J) groups

$\begin{array}{ccc}\text { Mean } & \text { Std. } & \text { Sig. } \\ \text { Difference } & \text { Error } & \\ (I-J) & & \end{array}$

\section{5\% Confidence} Interval

Lower Upper

Bound Bound

high school

textbook (group A)

Topnotch ( group

B)

Topnotch ( group B) touchstone( group C)

$-1.86$

-1.86
-1.46

.57

high school textbook

$1.86^{*}$

.57

.009

.009
.049

$-3.32$

$-2.92$

$-.407$

(group A)

Touchstone ( group C)

Touchstone ( group

C)

high school (group A)

.40

.40
$1.46^{*}$

$.57 \quad .786$

.407

3.325

textbook

Topnotch ( group B)

$-.40$

$-1.05$

1.859

2.925

*. The mean difference is significant at the 0.05 level. 
As it is displayed in Table 5, the highest mean difference was reported between "group B" and the "group $A$ " with mean difference of (1.86). On the other hand, the lowest mean difference was shown between groups B and $\mathrm{C}$ (mean difference $=.40$ ). Based on the findings of the analyses, in the second place, the "group C" performed better than the "group $A$ " who worked on high school textbooks. In other words, group A performed lower than the other two groups.

Table 6

Paired Samples Test for the Pre and Post Tests

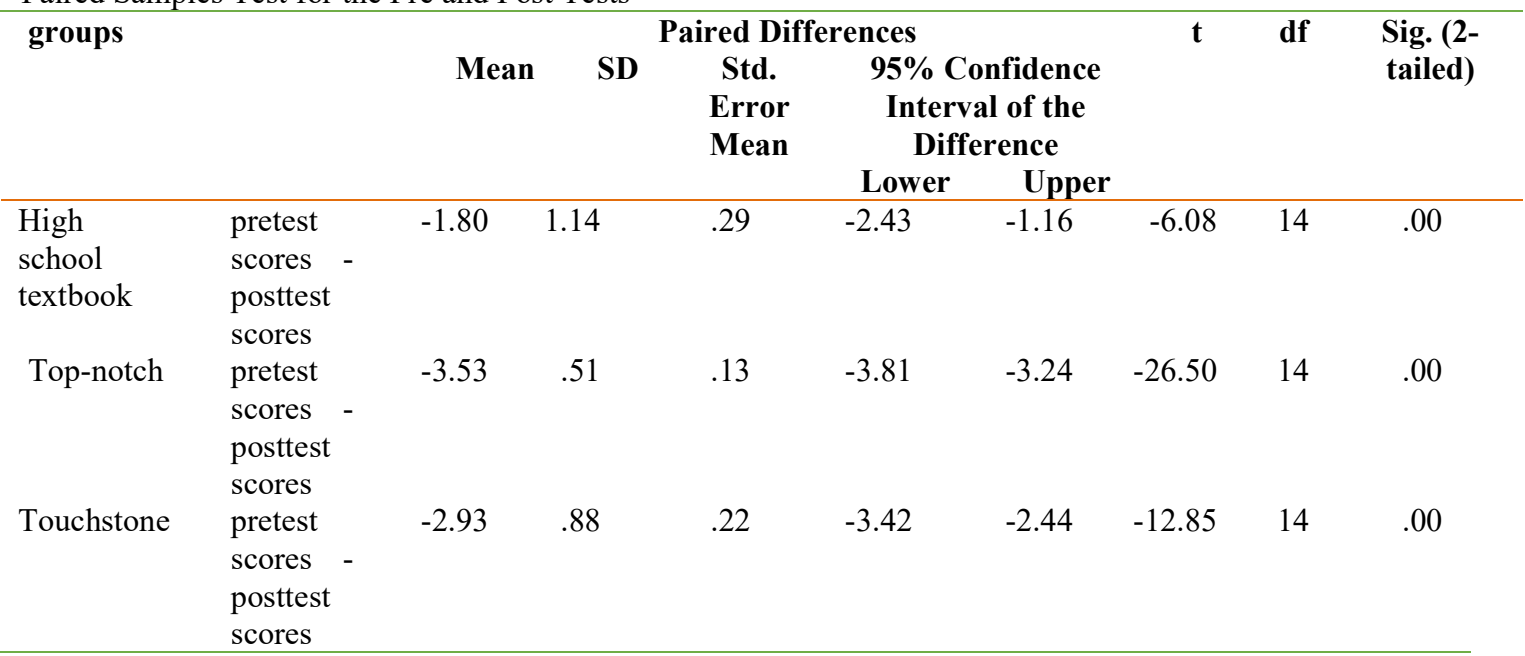

As it was shown in Table 6, "group B" outweighed the other two groups in relation to their reading comprehension performance. The findings also revealed that providing instruction on cohesive elements significantly affected EFL learners' reading comprehension for all the three groups $(\mathrm{P} \leq .05)$. However, the participants of group A progressed relatively lower than the other two groups (mean difference between pre and posttests $=1.80$. This meant that although awareness raising through explicit instruction of textual cohesive elements assisted the three groups to improve their reading comprehension and group (A) performed significantly different from their pretest on reading test $(\alpha=.00)$, they had relatively less progression compared to groups $\mathrm{B}$ and $\mathrm{C}$. This might be due to the weak cohesive elements found in high school textbooks. On the other hand, as the extent of textual cohesive elements used in top- notch was comparatively high, the specific treatment (awareness raising on textual elements) was more successful for the group who worked on top- notch book. Moreover, the participants' performance on third group (who had worked on touchstone) was better than that of group A.

\section{General Discussion}

This study focused on the effect of textual cohesion of teaching materials on Iranian intermediate EFL learners' reading comprehension ability. At the outset, this study tried to find out answer to the following question:

1. Does the difference in textual cohesion of different teaching materials have any significant effects on Iranian intermediate EFL learners' reading comprehension?

On the basis of the research question, the following hypothesis was formulated:

$\mathbf{H}_{\mathbf{0}}$ : the difference in textual cohesion of different teaching materials has no significant effects on Iranian intermediate EFL learners' reading comprehension.

As it was mentioned in Chapter Four, there was no significant difference among the groups at the reading comprehension pretest, whereas there were crucial differences among them at posttest. Those participants for whom the reading sections of two books touchstone and topnotch were used, showed better performance in posttest of the experimental groups; and also after the investigating of cohesion devices in all books (Topnotch and touchstone and high school English book) it was cleared that the books which were used for experimental groups (Topnotch and touchstone), had more cohesive devices than book which control group used (high school English book). Therefore the null hypothesis was rejected.

The results of the present study supports the findings of the previous studies done by Mohseni and Behforouz (2013) and also the finding of the study done by Rostami and Gholami (2016) comparing and contrasting the frequency of the use of cohesive devices in Iranian pre-university EFL textbook and in the headway as an EFL institute textbook..

Bloor (1995, p. 65) believes that as a means of communication texts play a very important role in getting the meaning across others. Having very different types (literary/expressive, scientific/informative and so on) they are expected to meet the expectation of different-purposed readers. In other words, no matter what type it may 
be, every text ought to address certain receivers who read it for a specific purpose like to get information, to read for fun etc.

\section{Conclusion}

Based upon the results yielded in the study several conclusions are drawn. The overall aim of the present study was to assess whether textual cohesion was effective in classroom setting and whether it was suitable for practical use by students to improve reading comprehension skill. The data analyzed revealed that textual cohesion led to significantly better performance of the intermediate students when comparison was made with respect to control group Furthermore, the higher performance of the experimental groups revealed that textual cohesion had a significant role at reading comprehension of students.

Comparing the cohesive elements found in the three teaching materials in this study, naming Topnotch, Touchstone, and high school English book, the more elements found in the passage, the better comprehension achieved by the learners. The participants in the two experimental groups using Topnotch and Touchstone books performed better than those studying high school English book.

\section{References}

Bloor, T. B. (1995). The Functional Analysis of English. London, New York: Arnold

Carrell, P. (1982). Cohesion is not coherence. TESOL Quarterly, 16, 479-488.

Graesser, A. C., McNamara, D. S., Louwerse, M. M., \& Cai, Z. (2004). Coh-Metrix: Analysis of Text on Cohesion and Language. Behavioural Research Methods, Instruments and Computers, 36, 193-202. doi: 10.3758/BF03195564.

Graesser, A. C., Gernsbacher, M. A., \& Goldman, S. R. (2003). Introduction to the Handbook of discourse processes (pp. 1-24). Routledge.

Halliday, M.A.K. and R. Hasan (1976) Cohesion in English. London: Longman. Mackay, R. and A. Mountford(1976) Reading for information. In E.M. Anthony and J. Richards (Eds.) Reading: Insights and Approaches. Singapore: Singapore University Press.

Halliday, M. A. K. \& Hasan, R. (1976). Cohesion in English. London. Longman.

Hinkel, E. (2001). Matters of cohesion in L2 academic texts. Applied Language Learning, 12(2), 111-132.

Horiba, Y. (1996). Comprehension processes in L2 reading: Language competence, textual coherence, and inferences. Studies in Second Language Acquisition, 18(4), 433-473. doi: 10.1017/S0272263100015370

Kintsch, W. (1998). Comprehension: A paradigm for cognition. New York: Cambridge University Press

McNamara, D.S. (2001). Canadian Journal of Experimental Psychology, 55, 51-62.

Mcnamara, d.s.,kintsch,w. (1996). Proceeding of the eighteenth annual meeting of the cognitive science society (pp.104-109).AustinTX: cognitive science society.

Mohseni, A. \&Behfrouz,B.(2013). The Statistical Investigation of Teaching and Examining Lexical Cohesion on the Ground of Iran EFL Educational Context from Theory to Practice. International Research Journal of Applied and Basic Sciences. ISSN 2251-838X / Vol, 7 (13): 972-978.

Mozaffar-Zadeh,L. (1998). A contrastive study of lexical cohesion in English and Persian research articles. English Language Teaching, 4, 4-16.

O'Reilly, T. \& McNamara, D.S. (2007b). Reversing the reverse cohesion effect: good texts can be better for strategic, high-knowledge readers. Discourse Processes, 43, 121-152. doi: 10.1080/01638530709336895.

Rostami,A,. \&Gholami,A..(2016). Use of cohesive ties in English as a foreign language students' writing. Iranian of Applied Language Studies, 2, 137-156.

Sadeghi K (2007). The key for Successful Reader-Writer Interaction: Factors Affecting Reading comprehension in L2 Revisited. Asian EFL journal 9(3).

Yang, L. \& Sun, M. (2012). The use of cohesive devices in argumentative writing. TESOL Journal, 23(1), 31-48. 